\title{
Efecto de la adición de fertilizantes inorgánicos compuestos en la degradación de hidrocarburos en suelos contaminados con petróleo
}

\author{
Jenny Liliana Pardo Castroㅁ, Maria Carolina Perdomo Rojas ${ }^{1}$ y Joaquín L. Benavides \\ López de Mesa². \\ ${ }^{1}$ Ingeniería Ambiental y Sanitaria, Universidad De La Salle. ${ }^{2}$ Licenciado en estudios mayores en Biología MSc. Microbiología. \\ Docente, Universidad de La Salle. Bogotá D.C., Colombia. \\ Recibido:28-05-2004; Aceptado:02-09-2004
}

\section{Resumen}

Actualmente, uno de los problemas ambientales importantes es la contaminación de ecosistemas terrestres por derrames de hidrocarburos principalmente del petróleo y sus derivados, que ocurren en actividades de explotación y transporte de los mismos. En Colombia, además de lo mencionado se dan por incursiones violentas contra la infraestructura petrolera por parte de grupos al margen de la ley. Para dar solución a esta problemática, existen métodos de tratamiento para recuperar suelos contaminados, como es la técnica de biolabranza (landfarming) adicionando nutrientes inorgánicos. En esta investigación se evaluó dicha técnica, in vitro, a través de un diseño de 6 unidades experimentales (UE) que contenían suelo contaminado con petróleo crudo; tres UE fueron tratadas con fertilizante inorgánico Triple 15, y las otras tres fueron tomadas como control biótico. La efectividad de la biolabranza se determinó por medio de análisis del pH, porcentaje de humedad, temperatura, conteos de microorganismos heterótrofos totales y número más probable de microorganismos degradadores de petróleo, nutrientes e hidrocarburos totales, durante un período de experimentación de cuatro meses. Al final del tiempo de experimentación, para el tratamiento de biolabranza con adición de nutrientes, se lograron porcentajes de remoción altos de TPH's, hasta de un 91\%, alcanzando concentraciones finales de TPH's de 2028 ppm, en comparación con el control biótico en el cual se obtuvieron porcentajes de remoción hasta del 65\% y concentraciones finales de 8049 ppm de TPH's; de manera que se logró demostrar que la adición de nutrientes optimiza el proceso de degradación de hidrocarburos en suelos.

Palabras Claves: contaminación, hidrocarburos de petróleo, fertilizante inorgánico, biolabranza, degradación

\section{Abstract \\ Effect in Laboratory of addition of inorganic fertilizers made in degradation of hydrocarbon on contaminated soil by oil}

At present one of the most important environmental problems is contamination of soil ecosystem by hydrocarbon spilling mainly of oil and its derivates which occurs when oil is explored or transported. Furthermore in Colombia it occurs due to violent assaults made by men outside of law against petroleum infrastructure. To solve this problem there are treatment methods to recover contaminated soil as Landfarming technique, adding 
inorganic nutrients. In this research this technique was evaluated in vitro, through a design of six experimental units (EU) which contained contaminated soil with crude oil; three EU were treated with Triple 15 inorganic fertilizer and the other three were taken as biotical control. Landfarming effectiveness was determined by $\mathrm{pH}$ analysis, humidity percent, temperature, count of total heterotrophic microorganisms, and probable number of oil degrades microorganisms, nutrients and total hydrocarbons for a four month experimental period. At the end of that period, in Landfarming treatment with nutrients added was achieved a high remotion percentage of TPH up to $91 \%$, getting final TPH concentration of $2028 \mathrm{ppm}$ comparing biotic control in which the remotion percentage achieved up to $65 \%$ and a TPH final concentration was $8049 \mathrm{ppm}$ thus, it could demonstrate that nutrient addition optimizes the degrading hydrocarbon process in soil.

Key Words: contamination, petroleum hydrocarbon, inorganic fertilizers, landfarming, degradation.

\section{Introducción}

Uno de los problemas ambientales más importantes de la actualidad es la contaminación de ecosistemas terrestres y acuáticos por derrames de hidrocarburos de petróleo y sus derivados. En el caso del suelo, las principales consecuencias ambientales que se presentan después de un evento de contaminación por hidrocarburos son: la reducción o inhibición del desarrollo de la cobertura vegetal del lugar del derrame, cambios en la dinámica poblacional de la fauna y la biota microbiana y contaminación por infiltración de cuerpos de agua subterráneos. Además del impacto ambiental negativo, los derrames de hidrocarburos generan impactos de tipo económico, social y de salud pública en las zonas aledañas al lugar afectado.

Las principales fuentes de contaminación por hidrocarburos en la actualidad son las actividades de explotación y transporte del petróleo. En Colombia, además de lo anterior, se presentan derrames de crudo en los sistemas de conducción debido a incursiones violentas de grupos al margen de la ley, entre los años 1986 y 1998 dichas incursiones ocasionaron el derramamiento de cerca de dos millones de barriles de petróleo, 7.6 veces el petróleo que se derramó en el desastre del buque Exxon Valdés entre Alaska y Canadá el 24 de marzo de 1998 (1).

www.unicolmayor.edu.co
En los ecosistemas terrestres, el suelo representa el medio físico que sustenta la vida de diversas especies, tanto animales como vegetales. La materia orgánica e inorgánica del suelo da cabida a la coexistencia de una gran cantidad de microorganismos que se adaptan a sus características físicas y químicas aún cuando estas sean variables. Los microorganismos tienen una gran importancia ecológica en los ecosistemas terrestres, pues cumplen la función de descomponer sustancias orgánicas de desecho en sus componentes básicos, los cuales se metabolizan junto con los nutrientes obtenidos del suelo, para generar nueva biomasa y llevar a cabo sus funciones vitales.

Químicamente, el petróleo es una mezcla de hidrocarburos compuestos formados principalmente por carbono e hidrógeno con contenidos menores de otros elementos como azufre, oxígeno, nitrógeno o trazas de metales, dependiendo del lugar de donde provengan. Los eventos de contaminación pueden ser remediados mediante eventos naturales que ocurren en el medio contaminado. Por ejemplo, en suelos se presenta el proceso de atenuación natural, capacidad de los suelos para degradar cantidades de sustancias orgánicas; fundamentalmente ligado a procesos metabólicos en microorganismos (biodegradación), pero también a procesos físicos y químicos como lavado, volatilización, fotodescomposición e hidrólisis; así como los de inmovilización por adsorción y formación de enlaces con arcillas, oxi-hidróxidos, entre otros (2). 
En general, los hidrocarburos de petróleo son compuestos intermedios entre altamente biodegradables y difícilmente biodegradables. La biodegradación de hidrocarburos en suelos se puede ver afectada por diversos factores físicos y ambientales del lugar del derrame, como la temperatura; esta tiene una gran influencia en la biodegradación por su efecto sobre la naturaleza física y química del petróleo.

Cuando la temperatura es baja, la viscosidad del petróleo aumenta variando su solubilidad en agua y se disminuye la volatilización de algunas fracciones tóxicas que pueden afectar la actividad degradadora de los microorganismos. Con temperaturas muy altas, se incrementa la toxicidad de los hidrocarburos inhibiendo la actividad microbiana. El rango de temperatura más apropiado para la biorremediación se presenta entre $30^{\circ} \mathrm{C}$ y $40^{\circ} \mathrm{C}$, a la que se intensifica la actividad enzimática de los microorganismos acelerando al máximo los procesos de biodegradación.

La biodegradación de hidrocarburos requiere la oxidación de los sustratos por oxigenasas siendo necesaria la presencia de oxígeno molecular en el medio. La concentración de oxígeno es una variable limitante para las tasas de degradación de los hidrocarburos; si el contenido de oxígeno en el suelo es muy bajo algunas porciones del medio pueden volverse anaeróbicas y afectar de manera negativa la biodegradación $(3,4)$. La oxigenación del suelo permite la volatilización de los compuestos tóxicos (5).

En cuanto a la capacidad de retención de agua y humedad, la biodegradación de hidrocarburos en ecosistemas terrestres puede ser limitada por la cantidad de agua disponible en el medio para el crecimiento y metabolismo de los microorganismos. Diferentes estudios realizados reportan que las tasas óptimas de biodegradación se dan cuando la saturación de agua en el suelo se encuentra en el rango de 30 a $90 \%$, en valores menores la degradación se ve inhibida $(6,7)$.

Correspondencia: revistanova@unicolmayor.edu.co
En lo referente al $\mathrm{pH}$, la mayoría de bacterias heterótrofas se desarrollan óptimamente en $\mathrm{pH}$ cercanos a la neutralidad, por lo cual es de esperarse que $\mathrm{pH}$ extremos en el medio afectarán de manera negativa a las comunidades microbianas inhibiendo su capacidad para degradar hidrocarburos. Algunos estudios han establecido que el rango óptimo de $\mathrm{pH}$ para la biodegradación de lodos aceitosos en suelo se encuentra entre 5 y $7.8(7,8)$.

Otro factor de importancia es la adición de nutrientes, los cuales son necesarios para el desarrollo de la actividad microbiológica y pueden ser divididos en dos clases: macronutrientes y micronutrientes (9).

La adición de hidrocarburos al suelo aumenta la cantidad de carbono disponible en el medio para la actividad metabólica de los microorganismos, si esto ocurre en lugares donde la concentración de nutrientes inorgánicos como N y $\mathrm{P}$ es baja, produce una relaciones $\mathrm{C} / \mathrm{N}$ y $\mathrm{C} / \mathrm{P}$ muy altas lo cual es desfavorable para el crecimiento microbiano.

Debido a que la disponibilidad de N y P en el medio es un factor limitante en la degradación microbiana de hidrocarburos, se puede ajustar la proporción C/N/P mediante la adición al medio de urea-fosfato, fertilizantes N-P-K y sales de amonio y fosfato logrando de esta manera acelerar el proceso de biodegradación.

Dichos factores deben ser controlados al máximo para aumentar la eficiencia de biodegradación y lograr la recuperación del suelo en el menor tiempo posible. Actualmente se aplican técnicas de biorremediación bajo condiciones controladas, como la biolabranza que consiste en incorporar a un suelo, sedimentos o lodos contaminados con hidrocarburos en una delgada capa estimulando la actividad de la biota microbiana nativa aeróbica del suelo, mediante la aireación y/o adición de nutrientes y humedad (10).

La liberación excesiva de hidrocarburos al medio y la disposición inapropiada de los residuos de petróleo, hace necesario implementar métodos de tratamiento 
para la recuperación de los suelos afectados, para que sean ambientalmente aceptables y económicamente rentables. Dentro de la presente investigación se evaluó el efecto de la adición de nutrientes mediante la técnica de biolabranza.

\section{Materiales y métodos}

El presente estudio siguió un diseño experimental básico preprueba-postprueba.

Muestra: fué tomada de la estación experimental, Finca San Javier de la Pontificia Universidad Javeriana, ubicada en la vía Zipaquirá - Nemocón (Cundinamarca) con la cual se evaluó una alternativa de tratamiento para suelos contaminados con petróleo por medio de un proceso de biorremediación, en el que se valoró la adición de nutrientes $\mathrm{P}$ y $\mathrm{N}$, aplicando la técnica de biolabranza, durante un tiempo de experimentación de 4 meses.

Muestreo: inicialmente se tomaron muestras directas del suelo de la finca San Javier para análisis físicoquímicos. En el laboratorio externo del Instituto Geográfico Agustín Codazzi se practicaron los siguientes análisis preliminares: nitrógeno total $\left(\mathrm{N}-\mathrm{NO}_{3}, \mathrm{~N}-\mathrm{NH}_{4}\right)$ y extracción con $\mathrm{KCl}(2 \mathrm{~N})$. Se realizó cuantificación potenciométrica de $\mathrm{P}$ asimilable y cuantificación colorimétrica; se determinó densidad aparente por el método del terrón parafinado y carbono orgánico por el método de titulación de Walkley - Black. Posteriormente se delimitó un área de $15 \mathrm{~m}^{2}$, de la cual se removió la capa vegetal superficial presente y se tomaron muestras aleatorias excavando hasta una profundidad aproximada de $20 \mathrm{~cm}$; las muestras fueron empacadas en 24 sacos de polietileno con un peso aproximado de $250 \mathrm{~kg}$.

Adecuación y preparación del suelo: el suelo recolectado se mantuvo a la intemperie sobre polietileno negro calibre 4, realizando riego y volteo una vez por semana, durante un mes, con lo anterior la humedad relativa permaneció entre $30-60 \%$, parámetro calculado mediante el método aplicado por el Instituto Geográfico Agustín Codazzi. Para evitar la deshidratación y pérdidas por acción del viento, se recubrió con sacos de polietileno.

Determinación de línea base: se complemento la información del contenido de nutrientes ( $\mathrm{N}$ y $\mathrm{P}$ ), densidad aparente y contenido de carbono orgánico, obtenida en los análisis preliminares, con la determinación del $\mathrm{pH}$ y el conteo de unidades formadoras de colonias (UFC) para heterótrofos.

$\mathrm{pH}$ : la determinación del $\mathrm{pH}$ del suelo, se desarrolló por el método 9045C, según Standard Methods (11).

Conteo de microorganismos heterótrofos totales: se utilizó agar infusión suelo mediante la técnica de la Sociedad Americana de Microbiología (7) y se realizó conteo de microorganismos heterótrofos por el método 9215 del Standard Methods $(12,13)$. Se prepararon diluciones $10^{-1}$ del suelo en agua buferizada (14). Posteriormente, se agitó 25 minutos a 200rpm, se dejó decantar por 30min y se realizaron diluciones sucesivas hasta $10^{-8}$. Las diluciones preparadas se sembraron en placas de agar nutritivo, por duplicado dejándolas incubar a temperatura ambiente $\left(17 \pm 3^{\circ} \mathrm{C}\right)$ durante 7 días, realizándose recuento de unidades formadoras de colonias.

Contaminación del suelo con petróleo: el suelo fue contaminado con $24 \mathrm{~L}$ de petróleo crudo tipo castilla, con gravedad API 12, distribuido de manera homogénea y posteriormente tamizado para lograr un tamaño de partícula uniforme. Se cubrió con polietileno y se dejó reposar durante 4 días para lograr que el contaminante impregnara completamente el sustrato; al cabo de este tiempo se realizó volteo con el fin de permitir la volatilización de las fracciones de hidrocarburos de cadenas cortas. Se analizaron dos muestras compuestas de 1 kilo, para determinar la concentración de hidrocarburos totales de petróleo (TPH) por el método de luz infrarroja y se determinó la concentración inicial de nitrato, amonio y fósforo asimilable.

Montaje de los mesocosmos: se realizó un montaje de 6 mesocosmos (unidades experimentales - UE) 
en cajas de polipropileno con capacidad de 0.0312 $\mathrm{m}^{3}$, sin sistemas de drenaje que contenían suelo contaminado hasta una altura de $14 \mathrm{~cm}$. A tres UE se les adicionó fertilizante inorgánico Triple 15, T15, el cual contiene nitrógeno amoniacal y orgánico, fósforo asimilable $\left(\mathrm{P}_{2} \mathrm{O}\right)$ y potasio soluble $\left(\mathrm{K}_{2} \mathrm{O}\right)$ en una proporción equivalente al $15 \%$ por kilogramo de fertilizante y las otras tres se utilizaron como control biótico.

Balance de nutrientes: con base en la relación C: N: P 100:10:1, se adicionó un total de 308g de T15 a cada una de las 3 unidades experimentales; este fertilizante se distribuyó en el tiempo así: 50\% durante el primer mes de experimentación, $25 \%$ el segundo mes y el $25 \%$ restante en el tercer mes. Se humedeció y volteó una vez por semana durante los cuatro meses de investigación. El porcentaje de humedad relativa presente, se mantuvo entre 30 y $90 \%(3,15)$. Se controló semanalmente temperatura y humedad; la humedad se determinó según la técnica utilizada por el Instituto Geográfico Agustín Codazzi (7).

Muestreo del suelo contaminado: se realizó un muestreo compuesto; el suelo de las UE fue constantemente homogenizado proporcionando una distribución uniforme del contaminante, así como de los nutrientes adicionados. Las unidades experimentales no tenían un sistema de drenaje por lo que no se presentaron pérdidas significativas de hidrocarburos ni nutrientes por acción de la escorrentía o lavado del suelo. La selección de las muestras se realizó de manera aleatoria, tomando 8 muestras puntuales de la superficie de las UE por medio de una cuadrícula de $60 \times 40 \mathrm{~cm}$ (área superficial), subdividida en 77 recuadros de $5 \times 5 \mathrm{~cm}$, los puntos para tomar las muestras se seleccionaron por medio de números aleatorios y con el suelo recogido se conformaron dos muestras compuestas. Las muestras compuestas 1 y 2 (M1 y M2), de cada UE se obtuvieron mezclando 4 de las muestras puntuales para M1 y 4 para M2, de esta se tomaron submuestras con una cantidad de suelo necesaria para cada análisis de laboratorio.
Monitoreo del suelo contaminado: se monitorearon las características físicas, químicas y microbiológicas de cada una de las UE durante los 4 meses de experimentación se realizaron mediciones de temperatura y $\mathrm{pH}$ mediante el método 9045C (11). Estos tres parámetros fueron medidos una vez por semana. La determinación del pH y el conteo de microorganismos heterotrofos totales se llevó a cabo según la metodología descrita anteriormente.

Análisis del número más probable (NMP): se realizó en placas de 96 pozos para microtitulación; se utilizó petróleo refinado como fuente de carbono, medio Bushnell-Haas (16) e iodonitrotetrazolium violeta (INT) (6). Los datos obtenidos en dicho recuento fueron analizados con el software Most Probable Number Calculator version 4.04 desarrollado por la Agencia de Protección Ambiental de Estados Unidos (US EPA).

Medición de nutrientes: para determinar la concentración de nutrientes, se llevaron a cabo las mediciones de: $\mathrm{N}^{-\mathrm{NO}_{3}}$ y $\mathrm{N}-\mathrm{NH}_{4}$ con extracción por $\mathrm{KCl}(1 \mathrm{~N})$ y cuantificación potenciométrica y $\mathrm{P}$ asimilable con extracción por Bray II y cuantificación calorimétrica (7).

Determinación de los hidrocarburos totales de petróleo TPH's: se llevo a cabo mediante determinación gravimétrica (14). La extracción del hidrocarburo de las muestras de suelo, se llevó a cabo utilizando el método de extracción por agitación orbital con diclorometano como solvente (17).

Determinación de hidrocarburos policiclicos aromáticos $(P A H s)$ : se realizó mediante cromatografía líquida (HPLC). Las curvas de calibración se realizaron por medio del análisis de una ampolleta de $2000 \mathrm{ng} / \mathrm{ml}$, cuyo estándar contenía los 16 PAHs identificados por la USEPA como contaminantes prioritarios (18). Estas determinaciones fueron realizadas en la segunda o tercera semana de cada uno de los meses de experimentación.

Aislamiento de los microorganismos degradadores de hidrocarburos: se realizó durante el último mes de experimentación. Se tomaron 2 muestras de suelo de 
$0.1 \mathrm{~g}$, a partir de un muestreo compuesto realizado en cada UE, cada muestra se sembró en $50 \mathrm{ml}$ de medio mineral líquido Bushnell Haas $(\mathrm{BH})$ con $1 \mathrm{ml}$ de petróleo refinado como fuente de carbono. Los inóculos fueron colocados en agitador orbital a 120rpm por 3 días a temperatura ambiente. Posteriormente, se realizaron siembras por duplicado de $0.1 \mathrm{ml}$ de cada muestra en agar $\mathrm{BH}$, utilizando petróleo refinado como fuente de carbono, después de seis días de incubación a $37^{\circ} \mathrm{C}$ se observó el crecimiento de colonias sobre el medio de cultivo. A partir de la siembra inicial se realizaron tres resiembras en agar $\mathrm{BH}$ con la misma fuente de carbono e incubadas durante 7 días a $37^{\circ} \mathrm{C}$. Se realizó resiembra, selección de colonias e identificación por medio de pruebas bioquímicas Gram-Positive ID Kit BBL Cristal Identificación Sistems, de Becton, Dickinson and Company.

Análisis estadísticos: los datos obtenidos al desarrollar los análisis descritos anteriormente fueron procesados en el programa estadístico SPSS para determinar diferencias significativas entre los datos obtenidos en cada una de las unidades experimentales y entre el tratamiento con Triple 15 y el control biótico.

\section{Resultados}

Porcentaje de humedad: tuvo un comportamiento creciente entre los meses 0 y 2 , y decreciente entre los meses 2 y 4 con valores comprendidos entre 36 a $67 \%$ para cada una de las UE.

Temperatura, presentó un comportamiento creciente entre los meses 2 y 4 para cada una de las UE, manteniéndose dentro de un rango de 13 a $17^{\circ} \mathrm{C}$.

$p H$, presentó un comportamiento creciente desde la semana 0 hasta la 10 y un comportamiento decreciente desde la semana diez a la dieciséis, para cada UE, presentando datos entre un rango de 4.2 a 6.96 para $\mathrm{T} 15$ y de 4.7 a 6.8 para control biótico. Los valores de $\mathrm{pH}$ fueron más bajos en las UE de Triple 15, que los encontrados en UE de control biótico.

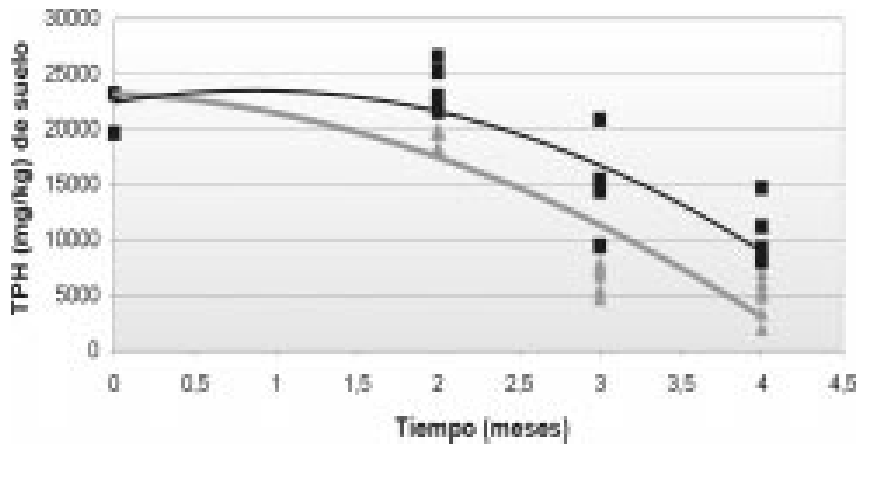

Figura 1. Correlación de concentración de TPH vs. tiempo de experimentación en UE de triple 15 y control biótico

Hidrocarburos totales de petróleo-TPHs, los resultados obtenidos de TPHs para las UE parten de un valor de $23280 \mathrm{mg} / \mathrm{kg}$ TPH en el primer mes, decreciendo hasta el cuarto mes. Los valores de TPH para T15 fueron más bajos que en el control biótico, llegando a un mínimo de $2028 \mathrm{mg} / \mathrm{kg}$ y $8049 \mathrm{mg} / \mathrm{kg}$ TPH respectivamente; presentando una diferencia estadísticamente significativa (Figura 1).

Las UE con T15 mostraron valores mas altos de remoción que el control biótico, alcanzando su máximo valor en el segundo mes con un 75\% de remoción, mientras que en el control biótico fue del $62 \%$ en el mismo mes. Los porcentajes de remoción total a lo largo de la investigación desde el primer mes al cuarto mes, en las UE con T15 tiene valores comprendidos entre el 67 y $91 \%$ y valores en los controles bióticos comprendidos entre el 37 y 65\% (Figura 2).

Los Hidrocarburos policiclicos aromáticos $P A H s$, tuvieron baja disminución a lo largo del tiempo de experimentación. Las concentraciones que mas disminuyeron fueron las de los compuestos pireno y $\mathrm{B}(\mathrm{k})$ fluoranteno (Figura 3 y 4).

Correlación de nutrientes, Triple 15, la tendencia de todos los nutrientes analizados para las UE que contenían T15 mostró un aumento progresivo, a pesar de algunas fluctuaciones en sus valores; presentando diferencias significativas entre ellos $(p<0.05)$ (Figura 5).

Correspondencia: revistanova@unicolmayor.edu.co 


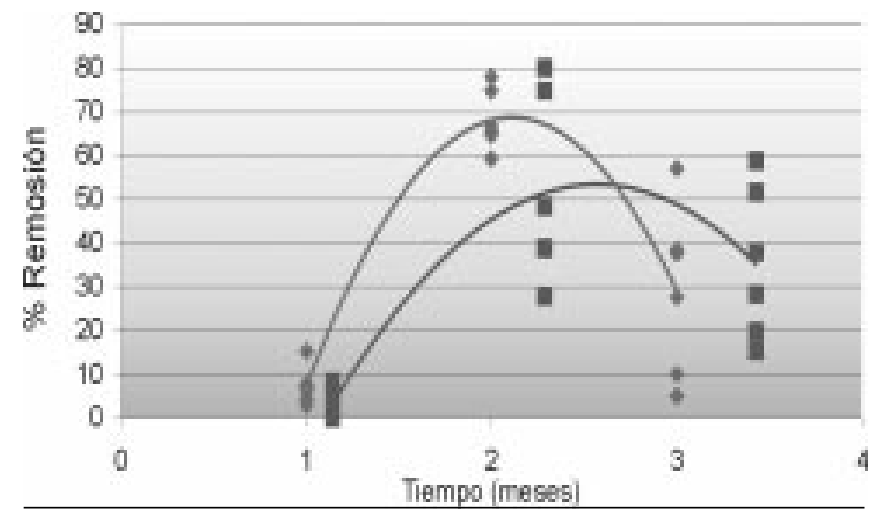

Figura 2. Porcentaje de remoción de TPH's vs. tiempo de observación en las UE de triple T15 y control biótico.

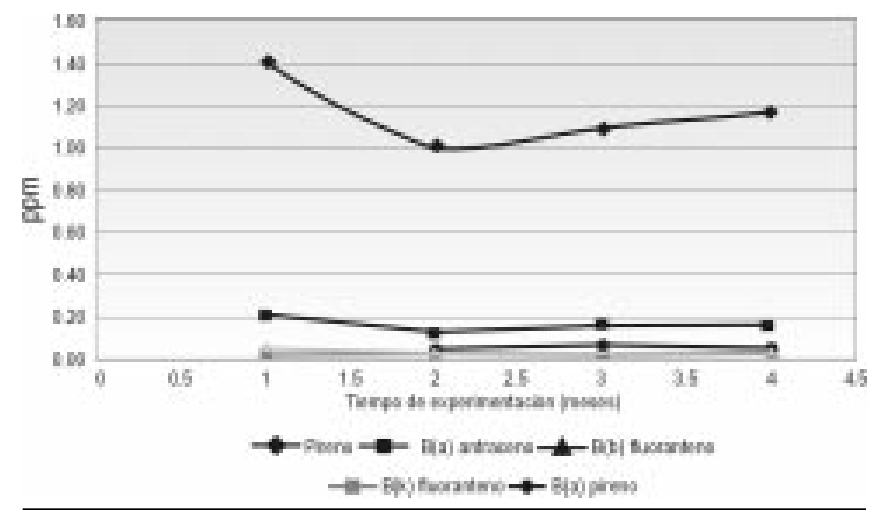

Figura 3. Concentración de PAHs vs. tiempo de experimentación para las UE Triple 15.

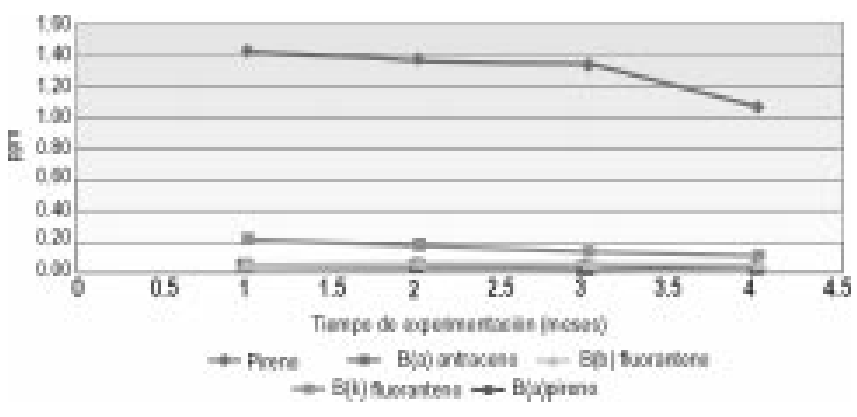

Figura 4. Concentración de PAH's vs. tiempo de experimentación para las UE de control biótico.

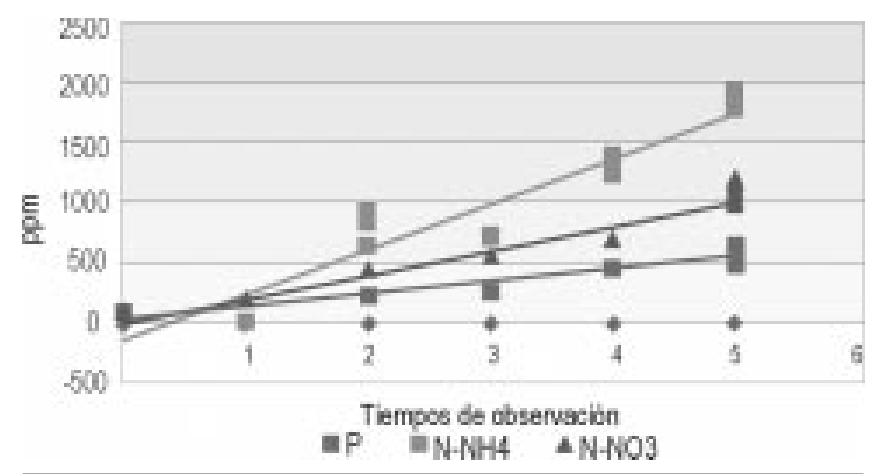

Figura 5. Correlación de nutrientes según tiempo de observación en T15.

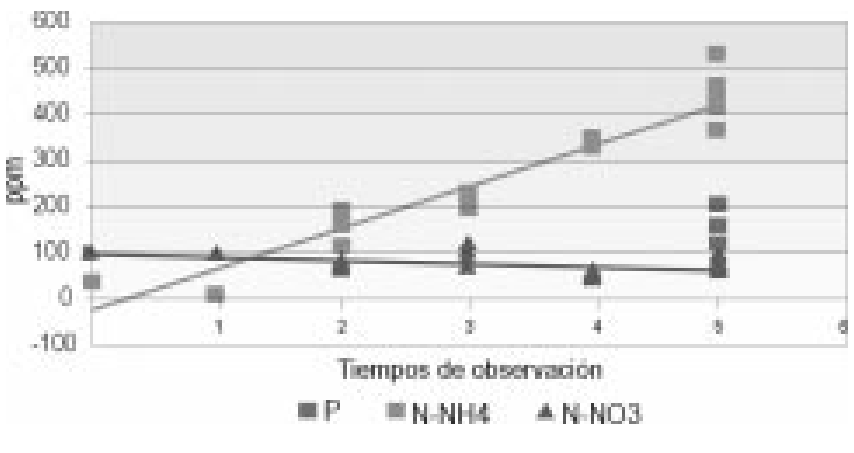

Figura 6. Correlación de nutrientes según tiempo de observación en control biótico.

Control Biótico de los nutrientes analizados en las UE, solo el $\mathrm{N}-\mathrm{NO}_{3}$ presentó un comportamiento decreciente, inversamente proporcional al que presentó el $\mathrm{P}$ y el N-NH$H_{4}$. Se presentaron diferencias estadísticamente significativas entre los diferentes nutrientes $(p<0.05)$ (Figura 6).

Microorganismos heterótrofos totales, el conteo de heterótrofos totales del suelo de estudio presentó un aumento progresivo desde $10^{4}$ hasta $10^{6}$ en cada una de las UE, sin una diferencia significativa entre ellos; sin embargo, los valores obtenidos en el UE con T15 fueron mayores que los del UE de control biótico; con un incremento poblacional que inicia en los meses 2 y 4 respectivamente (Figura 7).

Numero más probable NMP, los microorganismos degradadores de hidrocarburos presentaron un comportamiento creciente para la UE de control biótico, con valores logarítmicos comprendidos entre 5 y 9 y decreciente para la UE con T15 entre los meses 2 y 4 de experimentación, con valores que varían de 6 a 1.7 (Figura 8).

Aislamiento e identificación de microorganismos, los resultados del aislamiento de los microorganismos degradadores de hidrocarburos en los dos grupos de experimentación fueron: en las UE de T15 5 aislamientos de bacilos gram positivos y 1 aislamiento de levaduras. En las UE de control biótico 4 aislamientos de de bacilos gram positivos y 1 aislamiento de levaduras. Solo se pudieron identificar tres de las cepas aisladas, las cuales se muestran en la Tabla1. 


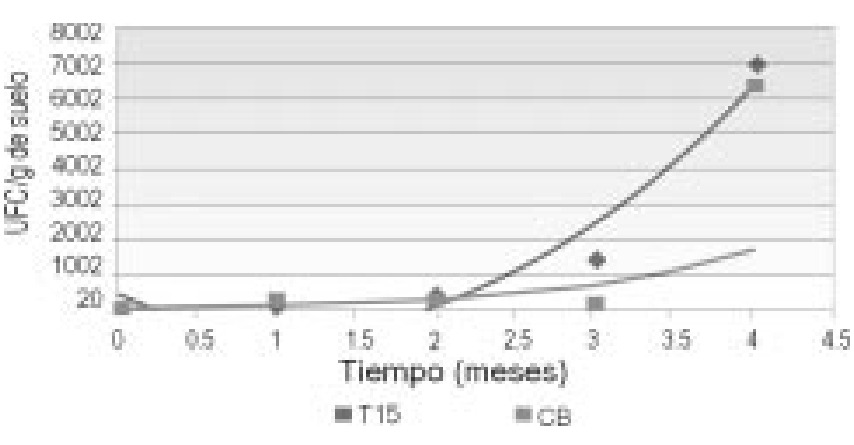

Figura 7. Correlación entre el comportamiento de microorganismos heterótrofos totales vs tiempo de observación en UE de triple $15 \mathrm{y}$ control biótico.

\section{Discusión}

Durante la investigación se conservó el rango de temperatura óptima de crecimiento al cual se encontraban adaptados los microorganismos del suelo de estudio; esto permitió un desarrollo satisfactorio de la biota microbiana ya que a dicha temperatura se presentan las tasas más elevadas de crecimiento y reproducción (19). De igual forma el porcentaje de humedad se mantuvo dentro del rango establecido para el proyecto (30-60\%), lo cual proporcionó las condiciones necesarias para el tratamiento de biolabranza.

$\mathrm{El} \mathrm{pH}$ del suelo disminuyó notablemente en cada una de las UE por la acción de los microorganismos debido a la transformación de materiales orgánicos y nitrificación, lo cual contribuye a que el suelo sea más ácido (20).

Al final de la presente investigación los análisis reflejaron un alto contenido de nutrientes, pues las UE eran sistemas cerrados; además la aplicación de T15 generó un aumento en el nitrato, amonio y P en las UE, debido a que estimularon los procesos de mineralización microbiana, liberando un exceso de nutrientes en forma inorgánica. Teniendo en cuenta

Tabla 1. Resultados de identificación taxonómica -BBL cristal.

\begin{tabular}{|l|l|}
\hline Nomenclatura & \multicolumn{1}{|c|}{ Identificación taxonomica } \\
\hline T15 1 A & Corynebacterium propinquum \\
\hline T15 2 E 31 & Bacillus brevis \\
\hline CB 1 A 11 & Bacillus brevis \\
\hline
\end{tabular}

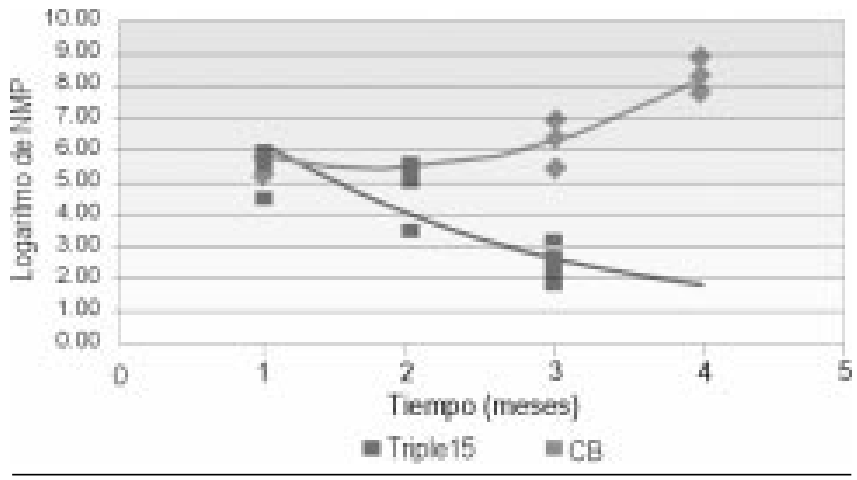

Figura 8. Correlación entre NMP vs. tiempo de observación en UE de T15 y control biótico.

que en las unidades experimentales de control biótico no hubo adición de nutrientes, el N-NH${ }_{4}$ presenta un incremento que se le atribuye a los procesos de mineralización.

Los comportamientos decrecientes para $\mathrm{N}-\mathrm{NO}_{3}$ y N$\mathrm{NH}_{4}$ se debieron a la asimilación de la totalidad del nitrógeno adicionado por parte de los microorganismos, por lo tanto no se presentó una liberación de $\mathrm{N}$ en forma inorgánica al medio. En las UE de control biótico la cantidad de $\mathrm{NO}_{3}$ presentó una disminución que pudo deberse a un proceso de reducción asimilatoria del nitrato.

Otra razón, pudo ser atribuida a la baja cantidad de microorganismos nitrificantes capaces de metabolizar todo el $\mathrm{NH}_{4}$ resultante de la mineralización de la materia orgánica.

Existen varias razones por las cuales el fósforo se presentó en concentraciones menores que las de nitrógeno en ambos grupos de observación; una de ellas es que el fósforo adicionado se adsorbe fuertemente por el complejo del suelo y en parte resulta inactivo (21), por otra parte las características ácidas del medio desencadenaron una fuerte fijación de los aniones sobre todo el fosfato que, se incorpora a las arcillas del suelo de estudio (22); esto provocó una inmovilización definitiva del mismo durante el cuarto mes cuando el $\mathrm{pH}$ llegó a ser demasiado ácido ( $\mathrm{pH} 4$ ), interviniendo en el grado de solubilidad del fósforo y por consiguiente en su aprovechabilidad (21), impidiendo así la presencia de fósforo asimilable. 
La adición de nutrientes en las UE de T15 ocasionó un incremento en la cantidad de microorganismos heterótrofos comparados con los de $\mathrm{CB}$ en las que fue mas bajo; esto demuestra que la abundancia de fuentes de carbono presentes en el sustrato al contaminar el suelo con hidrocarburo, puede intensificar la actividad microbiana, pero las bajas concentraciones de nutrientes retrasan los procesos de biodegradación de dichos contaminantes.

La contaminación del suelo con hidrocarburos generó un cambio drástico en las condiciones del medio que inducen a un período de adaptación en las comunidades microbianas, el cual fue más prolongado en las UE de control biótico debido a la carencia de altas concentraciones de nutrientes.

La disminución de las fuentes de carbono propias del suelo generó el consumo del hidrocarburo, lo cual ocasionó el incremento de los microorganismos degradadores. La densidad poblacional de dichos microorganismos depende de las relaciones carbono nitrógeno $(\mathrm{C}: \mathrm{N})$ presentes en el suelo; cuando dichas relaciones son altas las tasas de mineralización son bajas y cuando estas relaciones son bajas las tasas de mineralización son altas, lo cual se evidencia con la concentración de TPH's.

El aumento de microorganismos heterótrofos totales se debió a procesos cometabólicos, lo cual puede justificar el aumento de los heterótrofos totales en las unidades experimentales durante los últimos meses de experimentación. Los procesos cometabólicos y actividades bioquímicas sinérgicas en consorcios microbianos pueden conducir al reciclaje total de compuestos relativamente recalcitrantes (2).

Las diferentes cepas encontradas se desarrollaban simultáneamente en cooperación mutua, con lo cual se logró comprobar que la degradación de hidrocarburos requiere de la presencia de poblaciones mixtas con amplias capacidades enzimáticas para la degradación de mezclas complejas de hidrocarburos, petróleo crudo, en suelo (23) debido a que los microorganismos individuales pueden metabolizar solo un limitado rango de sustratos de hidrocarburos (24). Las bajas tasas de degradación de los PAH's se atribuyen a que los procesos de biodegradación de este tipo de compuestos son muy complejos y requieren mayores tiempos de tratamiento que los TPH's.

Los resultados obtenidos en la evaluación de la atenuación natural demostraron que la degradación de hidrocarburos por esta técnica requiere de un periodo de tratamiento mayor al evaluado para lograr una reducción de los TPH hasta niveles que no afecten la salud pública.

Los elevados niveles de remoción de hidrocarburos obtenidos en el tratamiento de biolabranza, demostraron que la adición de nutrientes inorgánicos; en combinación con altos porcentajes de humedad y condiciones aeróbicas agilizan los procesos de biodegradación de hidrocarburos en suelo.

La disminución en el porcentaje de remoción de hidrocarburos después de llevar a cabo los procesos de biolabranza, se debió a la cantidad de nutrientes con la cual fueron tratados, ya que los dos se mantuvieron bajo los mismos parámetros de humedad, temperatura y aireación.

Los conteos de microorganismos heterótrofos totales del suelo de estudio permitieron evidenciar, a lo largo del tiempo de experimentación, los diferentes comportamientos; periodo de adaptación a las nuevas condiciones del medio y la degradación intensiva del contaminante.

El desempeño de los microorganismos degradadores de hidrocarburos es óptimo cuando en el medio se presentan las condiciones ambientales y nutricionales adecuadas, las cuales generan en los microorganismos una capacidad de respuesta rápida a eventos de contaminación.

La disminución en las concentraciones de los PAH a lo largo del tiempo de experimentación fue baja

www.unicolmayor.edu.co 
debido a que este tipo de compuestos presentan poca degradabilidad y volatilidad, por lo tanto tienen un alto grado de persistencia en el medio.

La elección de un tratamiento para biorremediar el suelo contaminado con hidrocarburo no depende solo de la disponibilidad económica, sino también de las características propias del terreno, del contaminante y del impacto ambiental negativo que pueda este pueda generar.

\section{Referencias}

1. Empresa Colombiana de Petroleos. Un ecocidio irracional: los atentados contra la infraestructura petrolera. Bogotá: 2-3 p. 1998.

2. Lopéz M, Lerena P. Recuperación Asistida con Microorganismos. Microbios de Venezuela C.A; Ciudad Ojeda: 240-5. 1993

3. Leavy J , Colwell R. Microbial Degradation of Hidrocarbons in the Enviroment. Microbiological Reviews; 305-15. 1990

4. Wentz C. Hazardous Waste Management. Second Edition. McGraw-Hill International Editions; 224-35 p. 1995.

5. Geo Ambiental de México S.A. de C.V. Tecnologías Biológicas de Remediación. México: 400-403. 2000

6. Hains JR. Measurement of high hydrocarbon-degrading microbial populations by a 96-well plate most- probable-number procedure. Journal of industrial microbiology $1996 ;(16): 36-41$.

7. Olarte LJ, et al. Métodos analíticos del laboratorio de suelos. Cuarta edición. Bogotá: Instituto Geográfico Agustín Codazzi IGAC Subdirección agrológica, Ministerio de Hacienda y Credito Público; 1979. 90 y 136 p.

8. Kastner M, et al. Impact of Inoculation Protocols, Salinity, and $\mathrm{pH}$ on the Degradation of Polycyclic Aromatic Hydrocarbons (PAHs) and Survival of PAH-Degradating Bacteria Introduced into Soil. Applied and Environmental Microbiology 1997; 64 (1): 359-62.

9. Brock TD, Madigan MT. Biology of Microorganisms. Prentice Hall; 1997.

10. Environmental Protection Agency. Oil Spill Program: EPA; 1998 .
11. Method EPA-9045C. Soil and Waste pH, EPA; 1995.

12. Demain AI, Salomón NA. Department of nutrition and food science. Washington D.C: American society for microbiology; 20 p. 1986

13. Standard Method for the Examination for Water and Wastewater. $18^{\text {th }}$ edition. Edited by: Arnold E Greenberg, Lenores Clesceri and Andrew D. Eaton; 1992.

14. Standard Method for the Examination for Water and Wastewater. 20 $0^{\text {th }}$ edition. Edited by: Arnold E. Greenberg, Lenores Clesceri and Andrew D. Eaton; 2000.

15. Srinivasan N, Weaver R. Inoculants and Biodegradation of Crude Oil Floating on Marsh Sediments. Battelle Memorial Institute. Bioremediation Journal, 1997: p.89-96.

16. Aislabie J. Hydrocarbon-degrading Bacteria. Enumeration of hydrocarbon-degrading bacteria in the environment. Disponible en: URL: http://www.nexusresearchgroup.com/microbiology/ hcmicrobes.htm\#top.

17. Schwab AP, et al. Extraction of petroleum hydrocarbons from soil by mechanical shaking. Enviromental Science and technology 1999; 33(11):1940-45.

18. Hidrocarburos aromáticos policíclicos. Greenpeace. Disponible en: URL: http://archivo.greenpeace.org/informes/ Hidrocarburos.pdf.

19. Atlas RM, Bartha R. Microbial ecology: Fundamentals and Applications. Second Edition. Edited by: Benjamin/Cummings Publishing, Menlo Park, CA; p: 218, 305, 356, 361. 1987.

20. Agropstar. Conceptos de fertilidad y productividad del suelo. Agropstar; 12 p. 1990.

21. Salamanca Sanabria R. Suelos y fertilizantes. Universidad Santo Tomas. Usta; 1990. 135 p.

22. Programa de Edafología: Primer curso de ciencias ambientales: Universidad de Extremadura, departamento de biología y producción de los vegetales, área de edafología y química agrícola, Badajoz- España. Lección 5: Propiedades del suelo. Propiedades físico químicas. Reacciones del suelo. Última actualización mayo del 2001. Disponible en: URL: http://www.unex.es/edafo/ ECAL5PFQReaccion.htm.

23. Bossert I, Bartha R. The fate of petroleum in soil ecosystems. Cited by Leavy JG, Colwell R. Microbial Degradation of Hydrocarbons in the Environment Microbiological Reviews. 1990:308.

24. Britton LN. Microbial degradation of aliphatic hydrocarbons, cited by Leavy JG, Colwell R. Microbial Degradation of Hydrocarbons in the Environment. Microbiological Reviews. 1990: 308 .

Correspondencia: revistanova@unicolmayor.edu.co 